\title{
Genotoxicity and molecular response of silver nanoparticle (NP)-based hydrogel
}

\author{
Liming $\mathrm{Xu}^{1,2^{*}}$, Xuefei $\mathrm{Li}^{2}$, Taro Takemura ${ }^{3}$, Nobutaka Hanagata ${ }^{3}$, Gang $\mathrm{Wu}^{2}$ and Laisheng Lee Chou ${ }^{4 *}$
}

\begin{abstract}
Background: Since silver-nanoparticles (NPs) possess an antibacterial activity, they were commonly used in medical products and devices, food storage materials, cosmetics, various health care products, and industrial products. Various silver-NP based medical devices are available for clinical uses, such as silver-NP based dressing and silver-NP based hydrogel (silver-NP-hydrogel) for medical applications. Although the previous data have suggested silver-NPs induced toxicity in vivo and in vitro, there is lack information about the mechanisms of biological response and potential toxicity of silver-NP-hydrogel.
\end{abstract}

Methods: In this study, the genotoxicity of silver-NP-hydrogel was assayed using cytokinesis-block micronucleus (CBMN). The molecular response was studied using DNA microarray and GO pathway analysis.

Results and discussion: The results of global gene expression analysis in HeLa cells showed that thousands of genes were up- or down-regulated at $48 \mathrm{~h}$ of silver-NP-hydrogel exposure. Further $\mathrm{GO}$ pathway analysis suggested that fourteen theoretical activating signaling pathways were attributed to up-regulated genes; and three signal pathways were attributed to down-regulated genes. It was discussed that the cells protect themselves against silver NP-mediated toxicity through up-regulating metallothionein genes and anti-oxidative stress genes. The changes in DNA damage, apoptosis and mitosis pathway were closely related to silver-NP-induced cytotoxicity and chromosome damage. The downregulation of CDC14A via mitosis pathway might play a role in potential genotoxicity induced by silver-NPs.

Conclusions: The silver-NP-hydrogel induced micronuclei formation in cellular level and broad spectrum molecular responses in gene expression level. The results of signal pathway analysis suggested that the balances between anti-ROS response and DNA damage, chromosome instability, mitosis inhibition might play important roles in silver-NP induced toxicity. The inflammatory factors were likely involved in silver-NP-hydrogel complex-induced toxic effects via JAK-STAT signal transduction pathway and immune response pathway. These biological responses eventually decide the future of the cells, survival or apoptosis.

Keywords: Silver nanoparticle-based hydrogel (silver-NP-hydrogel), Genotoxicity, Global gene expression, DNA damage, Apoptosis and mitosis pathway, JAK-STAT signal transduction pathway

\section{Background}

Since the 2000s with the development of nanotechnology, various nanomaterials have been commercially used in a wide range of areas. Due to their antibacterial activity, silver-nanoparticles (NPs) are used commonly in medical products and devices, food storage materials, cosmetics, various health care products, and industrial products. In

\footnotetext{
* Correspondence: xuliming@nifdc.org.cn; Lchou@bu.edu

${ }^{1}$ Institute for Medical Devices Control, National Institutes for Food and Drug Control (NIFDC), No. 2 Temple of Heaven, Beijing 100050, China

${ }^{4}$ Goldman School of Dental Medicine, Boston University, 801 Albany Street, Suite 200, Boston, MA 02118-2392, USA

Full list of author information is available at the end of the article
}

medical applications, silver-NPs have been used for silverbased dressings [1,2], silver-coated catheters [3,4], silverbased hydrogel [5-7]. Silver-NP-hydrogel composites are composed of silver-NP and hydrogel which are used as carrier for silver particles. Most studies focused on manufacturing methods and antibacterial activity of silverNP-hydrogel composites [5-7].

In recent years, increasing data demonstrated that silverNPs could induce toxicity in vivo under a variety of exposure conditions including inhalation [8-10], orally [11,12] and via hypodermic injection [13]. Some in vitro studies revealed that silver-NPs could cause strong cytotoxicity in a broad spectrum of cells [14-25], such as germline stem cells 
[15], messenchymal stem cells (hMSCs) [16-18], BRL 3A rat liver cells [19], NIH3T3 cells [20], HepG2 human hepatoma cells [21], normal human lung fibroblasts (IMR-90), human glioblastoma cells (U251) [22,23], human normal bronchial epithelial (BEAS-2B) cells [24] and HeLa cells [25]. Many studies also reported that silver-NPs induced potential genotoxicity in several types of cells [21-24,26]. With the concerns about the safety and clinical risks associated with silver-NP-based medical products, however, a little is know about the molecular mechanism of silver-NP induced toxicity.

Metal ions including silver act as catalysts and can produce reactive oxygen species (ROS) in the presence of oxygen, which is considered to be a mechanism of toxicity and genotoxicity for metal nanomaterials. Acting as signal molecules, ROS, can promote cell cycle progression and induce oxidative DNA damage [19,27-29]. CBMN assay [30] is sensitive to ROS-mediated DNA damage, making it suitable for assessing the genotoxicity potentially induced by nanomaterials. Therefore, CBMN assay was selected to assess genotoxicity of silver-NP-hydrogel in this study.

Technique of microarray provides a way of studying biocompatibility of biomaterials at molecular level [31]. The global gene expression analysis using the microarray technique could gain profiling information of nanomaterial-cell interactions [25,32,33].

In this study, in vitro genotoxicity and molecular responses of silver-NP-hydrogel were assessed by CBMN assay and global gene expression analysis. The results provided scientific evidence for understanding the biosafety and potential clinical risk of silver-NP-based products.

\section{Results \\ Genotoxicity}

To know whether silver-NP-hydrogel has potential genetoxicity, a CBMN assay was conducted for assessing chromosome damage by silver-NP-hydrogel in HeLa cell cultures. The results were presented as the frequency of micronucleation per $1000 \mathrm{BNCs}$ (Table 1). The MMC treatment (positive control) showed a MNF of $20.6 \% \pm 2.47$, showing a significant difference compared to the $\mathrm{NaCl}$ solution treatment (negative control), which had a MNF of $2.5 \% \pm 0.79(P<0.05)$. It confirmed that the test system worked well. There was a significant increase in the $\mathrm{MN}$ frequency at $20 \mathrm{mg} / \mathrm{ml}(P<0.05), 40 \mathrm{mg} / \mathrm{ml}(P<0.05)$ and $60 \mathrm{mg} / \mathrm{ml}(P<0.05)$ of silver-NP-hydrogel exposure, this was not observed at the hydrogel treatment alone $(P=0.116)$. These results suggested that the silver-NPhydrogel induced chromosome damage in HeLa cells.

\section{Cellular response at molecular levels}

To assess the cellular response induced by silver-NPhydrogel exposure at the molecular level and the mechanisms of toxic effects, global gene expression and GO path-
Table 1 The CBMN assay of HeLa cells post-exposed to silver-NP-hydrogel and hydrogel for $\mathbf{2 4} \mathbf{h}$

\begin{tabular}{|c|c|c|c|c|}
\hline \multirow[t]{2}{*}{ Test } & \multirow[t]{2}{*}{ Dose } & \multirow{2}{*}{ FMN (\%) } & \multicolumn{2}{|c|}{$95 \%$ Confidence Interval for mean } \\
\hline & & & Lower Bound & Upper Bound \\
\hline $\mathrm{NC}(\mathrm{NaCl}$ sol & .) $50 \mu \mathrm{l}$ & $2.5 \pm 0.79$ & 5.3 & 44.7 \\
\hline Hydrogel & 60 mg/ml & $3.7 \pm 0.66$ & 20.7 & 53.3 \\
\hline \multirow[t]{3}{*}{ Silver-NP Gel } & $20 \mathrm{mg} / \mathrm{ml}$ & $7.0 \pm 0.82^{*}$ & 49.7 & 90.3 \\
\hline & $40 \mathrm{mg} / \mathrm{ml}$ & $8.67 \pm 0.32^{*}$ & 78.7 & 94.7 \\
\hline & $60 \mathrm{mg} / \mathrm{ml}$ & $9.47 \pm 0.3^{*}$ & 87.6 & 102.5 \\
\hline$P C(M M C)$ & $0.05 \mu \mathrm{g} / \mathrm{ml}$ & $120.6 \pm 24.7^{*}$ & & \\
\hline
\end{tabular}

Mitomycin C (MMC) was used as a positive control (PC). $\mathrm{NaCl}$ solution ( $\mathrm{NaC}$ sol.) was used as a negative control (NC). The results were presented as percentage of micronucleation frequency (FMN \%) in 1000 binucleation cells. The significance of positive control compared to negative control was identified using $T$-Test. The significance of all test samples compared to negative control was identified using ANOVA and Dunnett tests (2-sided).

* $P<0.05$. The data indicate the mean $\pm S D(n=3)$.

way analysis was performed using the DNA microarray technique. The graphical abstract of working process for global gene expression analysis was shown in Figure 1.

\section{The morphological changes of cells}

After exposing cells to $40 \mathrm{mg} / \mathrm{ml}$ silver-NP-hydrogel (contained $15.2 \mu \mathrm{g}$ of silver-NPs) for $24 \mathrm{~h}$ and $48 \mathrm{~h}$, the cells lost their normal epithelial cell morphology, becoming longer, and swelled. In contrast, cells exposed to hydrogel (without silver-NPs) did not show significant difference compared to the non-treatment control (Figure 2).

\section{Gene expression profiling}

According to the defined filtering criteria as described in "Materials and methods", the differentially expressed genes in both silver-NP-hydrogel and hydrogel alone groups, including up-regulated and down-regulated genes, are shown in Additional files 1, 2, 3, 4, 5, 6, 7 and 8. A total of 1,258 genes (Additional file 1) were up-regulated and 788 genes (Additional file 2) were down-regulated at $24 \mathrm{~h}$ exposure to silver-NP-hydrogel. Also, 1,532 genes (Additional file 5) were up-regulated and 824 genes (Additional file 6) were down-regulated at $24 \mathrm{~h}$ exposure to hydrogel alone. After the $48 \mathrm{~h}$ exposure, a total of 843 genes (Additional file 3) were up-regulated and 642 genes (Additional file 4) were down-regulated from silver-NP-hydrogel exposure. In contrast, 99 genes (Additional file 7) were upregulated and 370 genes (Additional file 8) were downregulated from exposure to hydrogel alone.

By comparing $24 \mathrm{~h}$ and $48 \mathrm{~h}$ gene expression profiling, it was observed that the $21.7 \%$ of genes that were upregulated at $24 \mathrm{~h}$ post-exposure to silver-NP-hydrogel were continuously highly expressed until the $48 \mathrm{~h}$ exposure (273 genes, Additional file 9) (Figure 3A). This suggested that the silver-NP-hydrogel continuously induced gene upregulation at $48 \mathrm{~h}$ exposure. In addition, $19.16 \%$ of the genes that were down-regulated at $24 \mathrm{~h}$ post-exposure, were 


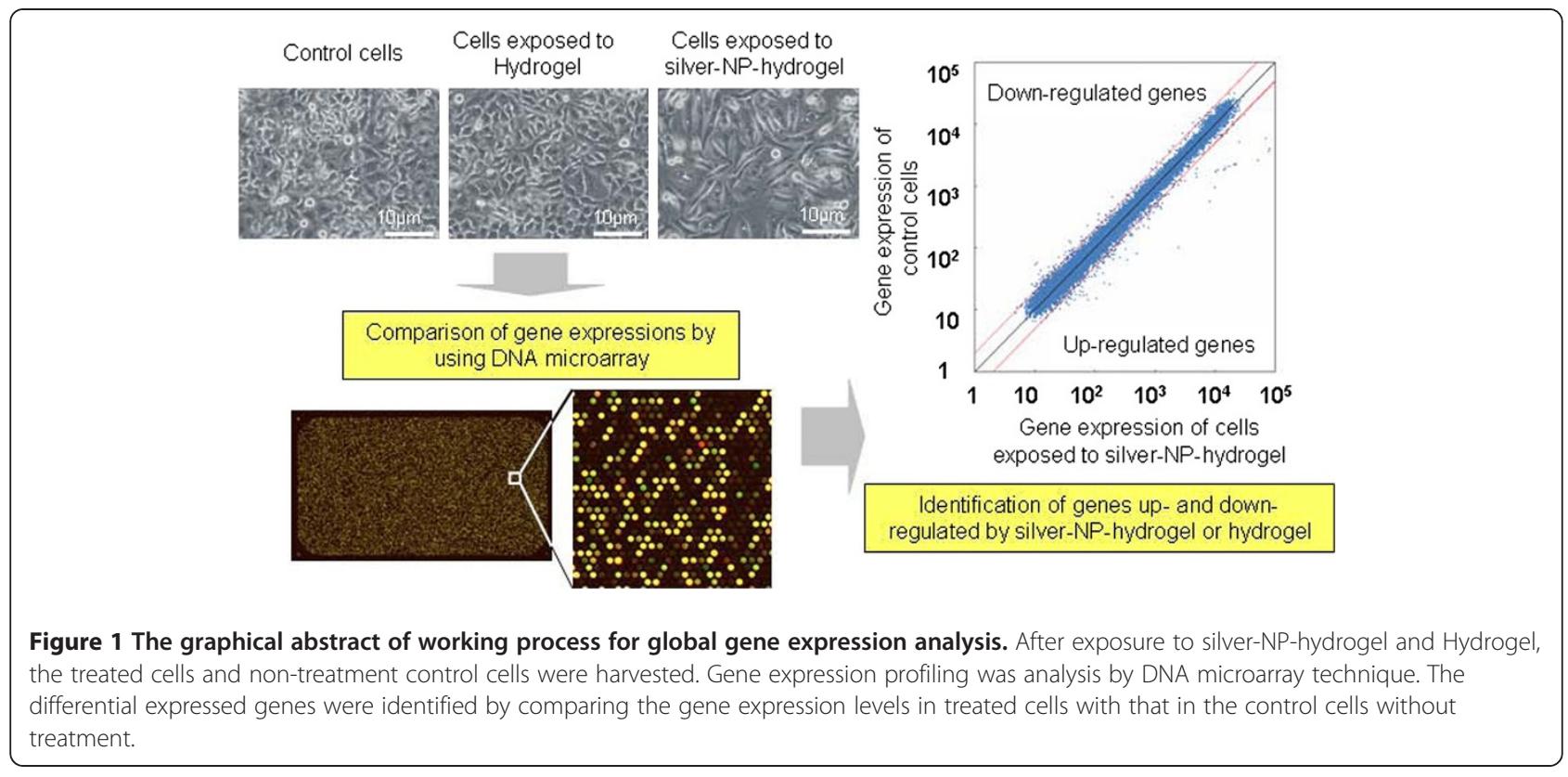

continuously lower-expressed until the $48 \mathrm{~h}$ exposure (151 genes, Additional file 10) (Figure 3A). This suggested that the silver-NP-hydrogel continuously caused gene downregulation at the $48 \mathrm{~h}$ exposure period.

In contrast, most of the up-regulated genes at $24 \mathrm{~h}$ exposure to hydrogel alone had recovered after continuous exposure up to $48 \mathrm{~h}$. Only $1.76 \%$ of up-regulated genes at $24 \mathrm{~h}$ exposure continuously showed higher-expression at $48 \mathrm{~h}$ (27 genes, Additional file 11) (Figure 3B). This observation suggested that the gene up-regulation was a transient response in the cells against the extracellular stimulation from the hydrogel. However, $16.75 \%$ of genes that were down-regulated at $24 \mathrm{~h}$ post-exposure to hydrogel alone, were continuously lower-expressed until $48 \mathrm{~h}$ exposure (138 genes, Additional file 12) (Figure 3B). These results suggested that down-regulated genes rather than upregulated genes might play a role in the cell response against hydrogel alone.

By further comparing changed genes common to both silver-NP-hydrogel and hydrogel alone exposure, it was found that, of the 843 up-regulated genes at 48 h silverNP-hydrogel exposure, only $3.91 \%$ of genes were common to those expressed at hydrogel alone exposure (33 genes, Additional file 13); and $96.09 \%$ of the genes were unique for silver-NP-hydrogel exposure (Figure 3C). For the 642 down-regulated genes at $48 \mathrm{~h}$ of silver-NP-

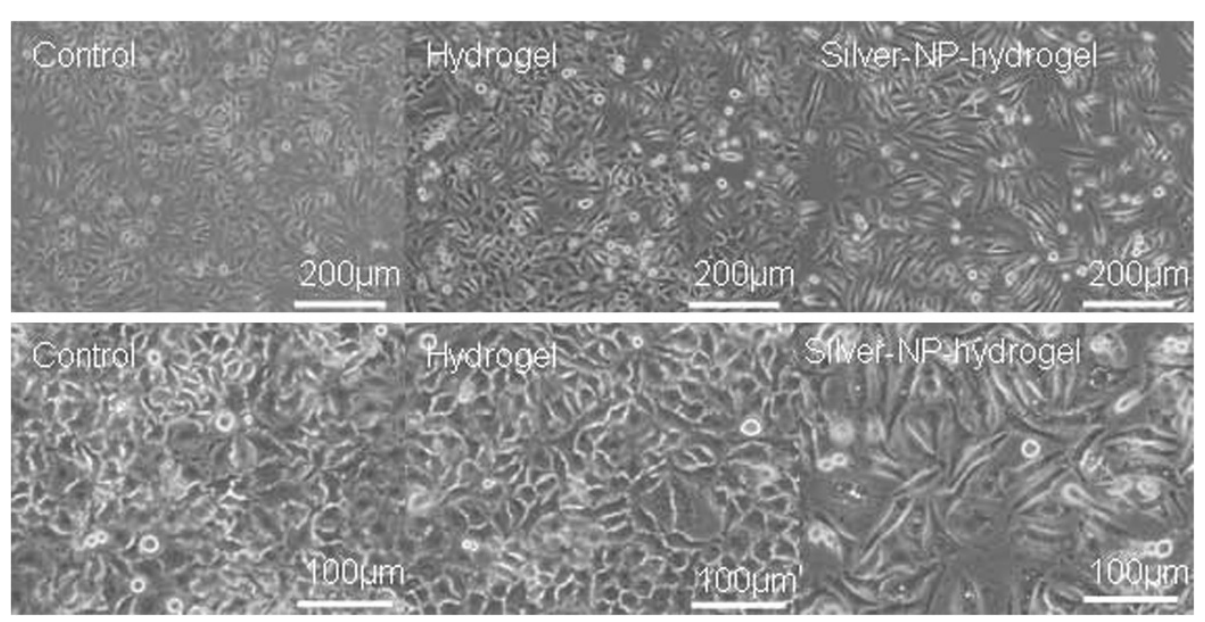

Figure 2 Cell morphological changes. The cells were post-exposed with silver-NP-hydrogel $(40 \mathrm{mg} / \mathrm{ml})$ and Hydrogel $(40 \mathrm{mg} / \mathrm{ml})$ as the study groups and with no treatment as a control for $24 \mathrm{~h}$ (up-panel, X 200) and $48 \mathrm{~h}$ (bottom-panel, X 400). The changes of cell morphology were visualized by light microscopy. 


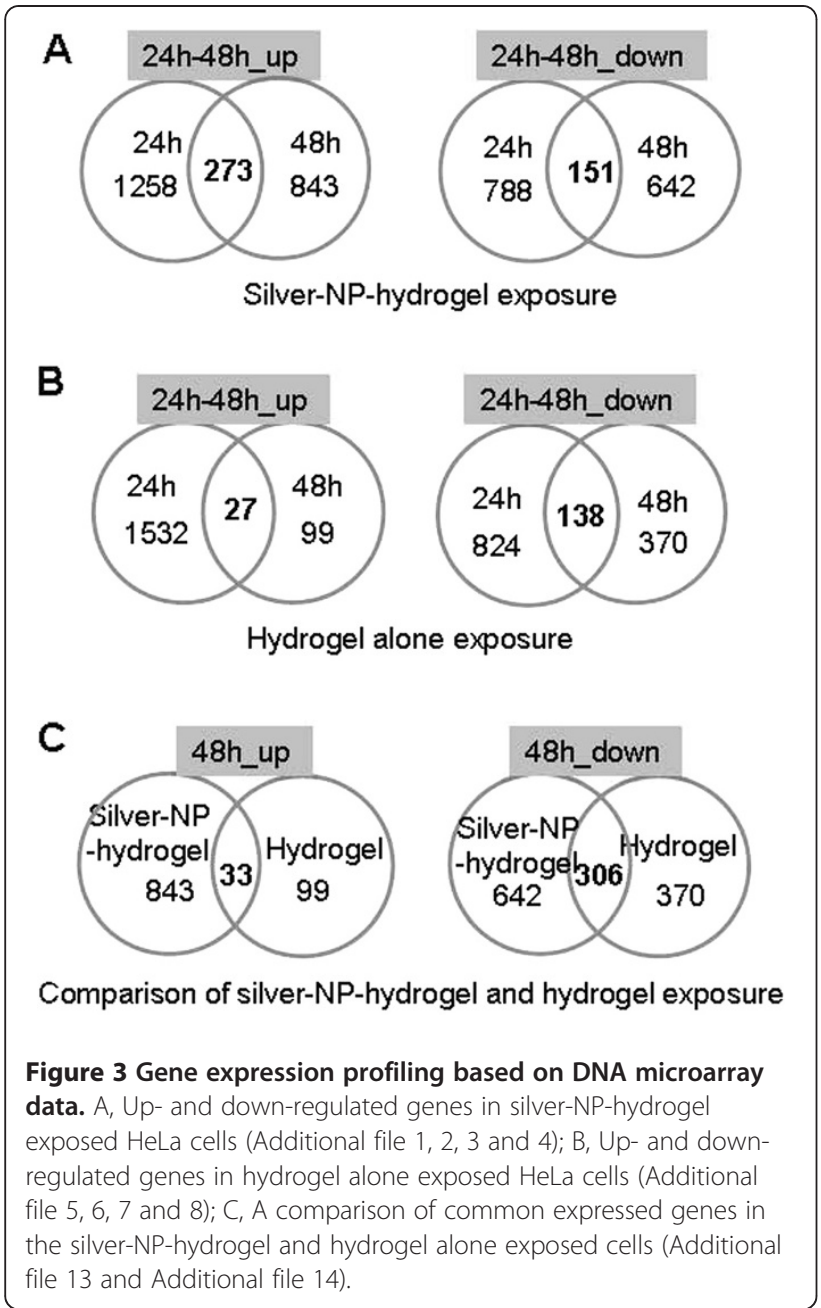

hydrogel exposure, 46.66\% (306 genes, Additional file 14) of genes were common to those expressed at hydrogel alone exposure; and $53.34 \%$ of the genes were unique changes for silver-NP-hydrogel exposure (Figure 3C). These results suggested that the up-regulated genes induced by silverNP-hydrogel could be mainly attributed to silver-NPs and that the down-regulated genes induced by silver-NPhydrogel could be attributed in part to silver-NP and hydrogel components. It was indicated that silver-NPs could play a key role in the silver-NP-hydrogel induced toxicity, while hydrogel components might also play a role in the toxic response to silver-NP-hydrogel by down-regulating some gene expressions.

\section{GO function analysis of differential expressed genes}

Based on gene ontology (GO) biological processes, the genes which were up- and down-regulated at $48 \mathrm{~h}$ of silverNP-hydrogel exposure were further analyzed using the program of GO Surfer. With the gene number-based signal pathway activation analysis, the GO pathway which has the- oretically significant activation $(\mathrm{p}<1.0 \mathrm{E}-03)$ was further picked-up as shown in Table 2 and Table 3.

Pathway analysis of GO/Biological processes showed that fourteen functional signal pathways were related to upregulated genes at $48 \mathrm{~h}$ of silver-NP-hydrogel exposure (Table 2), suggesting that the up-regulated genes might play an important role in adverse cell responses. These fourteen functional signal pathways were unique for silver-NPhydrogel exposed cells, but not common to hydrogel alone exposed cells, suggesting that the changes in functional signal pathways were attributed to silver-NPs. Under the same analysis method, in contrast, non-signal pathway which was theoretical significant activation was observed in upregulated genes at $48 \mathrm{~h}$ of hydrogel alone exposure (data not shown). In addition, the most up-regulated genes at $24 \mathrm{~h}$ exposure had recovered at $48 \mathrm{~h}$ of hydrogel exposure (Figure 3B). It was further suggested that the up-regulated genes induced by the hydrogel components might not affect cell function. Several pathways were related to down-regulated genes at $48 \mathrm{~h}$ of silver-NP-hydrogel exposure (Table 3). These included the nucleobase, nucleoside, nucleotide and nucleic acid metabolic processes pathway, cell cycle pathway and mitosis pathway. These results suggested that the down-regulated genes might cause cell damage by affecting cell proliferation, cell cycles and mitosis. The later two pathways, being unique to silver-NP-hydrogel exposure, were not common to hydrogel alone exposure, suggesting that the changes of these functional signal pathways are mainly

Table 2 GO function analysis of differential expressed genes at $48 \mathrm{~h}$ exposure of silver-NP-hydrogel

\begin{tabular}{lcc}
\hline Functional GO pathway & REF.-LIST*/Up-exp ${ }^{*} /$ expected $^{\text {\$ }}$ P value \\
\hline cell communication & $4365 / 231 / 174.28$ & $\mathrm{p}=1.04 \mathrm{E}-06$ \\
\hline cell-cell signaling & $1331 / 81 / 53.14$ & $\mathrm{p}=2.14 \mathrm{E}-04$ \\
\hline cell adhesion & $1333 / 77 / 53.22$ & $\mathrm{p}=8.67 \mathrm{E}-04$ \\
\hline signal transduction & $4191 / 215 / 167.34$ & $\mathrm{p}=2.37 \mathrm{E}-05$ \\
\hline $\begin{array}{l}\text { intracellular signaling } \\
\text { cascade (JAK-STAT cascade) }\end{array}$ & $1568 / 102 / 62.61$ & $\mathrm{p}=1.02 \mathrm{E}-06$ \\
\hline metabolic process & $8267 / 373 / 330.08$ & $\mathrm{p}=7.32 \mathrm{E}-04$ \\
\hline lipid metabolic process & $1119 / 94 / 44.68$ & $\mathrm{p}=7.32 \mathrm{E}-12$ \\
\hline $\begin{array}{l}\text { carbohydrate metabolic } \\
\text { process }\end{array}$ & $952 / 69 / 38.01$ & $\mathrm{p}=1.08 \mathrm{E}-06$ \\
\hline response to stimulus & $1798 / 119 / 71.79$ & $\mathrm{p}=7.96 \mathrm{E}-08$ \\
\hline transport & $2857 / 164 / 114.07$ & $\mathrm{p}=6.18 \mathrm{E}-07$ \\
\hline endocytosis & $575 / 43 / 22.96$ & $\mathrm{p}=9.23 \mathrm{E}-05$ \\
\hline cellular defense response & $457 / 38 / 18.25$ & $\mathrm{p}=2.75 \mathrm{E}-05$ \\
\hline immune system process & $2628 / 171 / 104.93$ & $\mathrm{p}=7.69 \mathrm{E}-11$ \\
\hline immune response & $756 / 52 / 30.19$ & $\mathrm{p}=1.41 \mathrm{E}-04$ \\
\hline
\end{tabular}

* reference list, that is all genes number related to the GO pathway;

\# up-expressed genes number in this study;

$\$$ expected minimum genes number for activating of signal pathway.

Based on the gene ontology (GO) biological process, the GO pathway, which has theoretically significant activation $(p<1.0 \mathrm{E}-03)$, related to up-regulated genes. 
Table $3 \mathrm{GO}$ function analysis of differential expressed genes at $48 \mathrm{~h}$ exposure of silver-NP-hydrogel

\begin{tabular}{|c|c|c|}
\hline Functional GO pathway & $\begin{array}{l}\text { REF.-LIST*/Down- } \\
\exp ^{*} / \text { expected }^{\$}\end{array}$ & $P$ value \\
\hline $\begin{array}{l}\text { nucleobase, nucleoside, nucleotide and } \\
\text { nucleic acid metabolic processes }\end{array}$ & $3825 / 138 / 81.84$ & $p=8.40 E-12$ \\
\hline cell cycle & $1840 / 62 / 39.37$ & $p=2.60 E-04$ \\
\hline mitosis & $635 / 27 / 13.59$ & $p=6.90 E-04$ \\
\hline \multicolumn{3}{|c|}{$\begin{array}{l}\text { * reference list, that is all genes number related to the GO pathway; } \\
\text { \# down-expressed genes number in this study; } \\
\text { \$ expected minimum genes number for activating of signal pathway. } \\
\text { Based on the gene ontology }(\mathrm{GO}) \text { biological process, the GO pathway, which } \\
\text { has theoretically significant activation ( } \mathrm{p}<1.0 \mathrm{E}-03) \text {, related to down-regulated } \\
\text { genes. }\end{array}$} \\
\hline
\end{tabular}

attributed to silver-NPs. These events were considered to be closely involved with cytotoxicity and genotoxicity. At $48 \mathrm{~h}$ of hydrogel exposure, three pathways related to downregulated genes were also showed theoretical significant activation. They included a metabolic process $(\mathrm{p}=4.02 \mathrm{E}-04)$, nucleobase, nucleoside, nucleotide and nucleic acid metabolic processes $(\mathrm{p}=1.69 \mathrm{E}-10)$ and the primary metabolic process $(p=2.97 \mathrm{E}-04)$. These results suggested that the down-regulated genes induced by hydrogel alone might have some effect on cell proliferation and metabolism.

\section{Real-time PCR verification of differential expressed genes}

To verify the reliability of differential expressed gene identified by the DNA microarray, five genes selected from upand down-regulated genes expressed in silver-NP-hydrogel $48 \mathrm{~h}$ exposure were further examined with real-time PCR detection. The results showed that the gene expression was basically consistent with that of the microarray analysis, indicating a good reliability and reproducibility of the microarray in the current study (Table 4).

\section{Discussion}

Genotoxicity evaluation is an idea assessment of biosafety at molecular level for nanomaterials-based medical devices. In this study, a significant increases in the micronucleation frequency (MNF) of HeLa cells was induced by the silverNP-hydrogel exposure at concentrations of 20-, 40-, and $60-\mathrm{mg} / \mathrm{ml}$ (in medium), compared to the negative control $(P<0.05)$, suggesting that the silver-NP-hydrogel has a potential risk of genotoxicity. The study also showed that hydrogel alone did not show significant change, compared to the negative control, suggesting that genotoxicity caused by silver-NP-hydrogel was attributed to silver-NPs. Kawata

Table 4 The gene expression detected by real-time PCR and detected by DNA microarray at $48 \mathrm{~h}$ exposure of silver-NP-hydrogel

\begin{tabular}{llllll}
\hline determination & IL1A & HMOX1 & DDIT3 & MT1F & PDGFRB \\
\hline Real-time PCR (2 $\left.{ }^{-\nabla} \nabla^{C t}\right)$ & 15.97 & 6.58 & 8.18 & 82.96 & 0.4 \\
\hline DNA microarray (fold changes) & 2.76 & 2.41 & 2.17 & 5.63 & -2.14 \\
\hline
\end{tabular}

et al. demonstrated that exposure to $1.0 \mu \mathrm{g} / \mathrm{ml}$ of silver-NPs (7-10 nm in size) induced MNF up to $47.9 \%$ in the HepG2 cell line [21]. AshaRani et al. reported that exposure at the $25 \mu \mathrm{g} / \mathrm{ml}$ of silver-NPs (6-20 $\mathrm{nm}$ in size) induced chromosomal aberrations in $10 \%$ of the IMR-90 normal cell line, and in $20 \%$ of the U251 cancer cell line [22,23]. In the comet assay and micronucleus (MN) assay for BEAS-2B cells, silver-NPs (43-260 $\mathrm{nm}$ in size, dispersed in medium) stimulated DNA breakage and MN formation in a dosedependent manner [24]. In this study, the size of silver nanoparticles contained in silver-NP-hydrogel ranged from $5 \mathrm{~nm}$ to $30 \mathrm{~nm}$ (observed by TEM, dispersed in water). Number of studies has reported for the in vivo genotoxicity and carcinogenicity by silver-NPs. Study by Kim et al. reported that there was no genotoxic effect in rats after 28 days oral exposure to Ag NPs [11]. Kim et al. also reported that no genotoxic effect in rats after 90 days inhalation of Ag NPs [34]. In contrast, however, our recent study reported that silver-NP-hydrogel induced micronuclei, nuclei disruption, chromatin concentration and cell apoptosis in rabbit reproductive organ tissues in silver-NPhydrogel administration through the vagina [35]. The difference of findings in potential genotoxic and carcinogenic risks of nanomaterials is possibly due to the insufficient characterization of test material, difference in the experimental design, use of different animal models and species, difference in dosimetry, and different targeting organs [36]. It was known that confirmation of asbestos nanofiber as a carcinogen in Japan took over 10 years [37]. Since the silver nanoparticles are still widely used clinically in some countries, it is important to gain a better understanding of their genotoxicity and carcinogenecity.

Two important molecular mechanisms were considered to be involved in the in vitro toxicity and genotoxicity induced by silver-NP-hydrogel, as further discussed below.

\section{The balance between anti-ROS-toxicity and DNA damage}

From the data in this study, the signaling pathways and regulatory proteins involved in anti-ROS-toxicity, DNA damage, apoptosis, cell cycles and mitosis might be associated with genotoxicity caused by silver-NP-hydrogel.

Metallothioneins (MTs) are considered to be essential biomarkers in metal-induced toxicity [38] as facilitating metal detoxification and protection from free radicals [39]. A report on heavy metal toxicity in Javanese medaka showed that MT upregulation occurs in silver mediated toxicity [40]. Hemeoxygenase-1 (HO-1) is an ROS sensor and a cryoprotective agent possessing antioxidant and antiinflammatory properties. HO-1 breaks down heme to antioxidant biliverdin, carbon monoxide and iron under stress conditions $[41,42]$. It was reported that oxidative stress response genes (superoxide dismutase 2, glutathione reductase 1, etc.) in mouse brain following silver-NP exposure were upregulated [43]. In the present study, 10 metal- 
lothionein genes (MT1F, MT1A, MT2A, MT1B, MT1G, MT1H, MT1X, MT1L, MT1M, MT1E), HO-1 and oxidative stress induced growth inhibitor 1 (OSGIN1) were significantly up-regulated at $48 \mathrm{~h}$ of silver-NP-hydrogel exposure [Additional file 5 and Additional file 6]. All these molecules are believed to protect cells against metalinduced ROS toxicity. Metal ions including silver act as catalysts and can produce reactive oxygen species in the presence of oxygen, which is thought to be a mechanism of toxicity. Previous studies showed that silver-NPs increase the production of intracellular ROS [20]. The ROS can act as signal molecules promoting cell cycle progression, and can induce oxidative DNA damage [27-29]. We previously reported that HeLa cells exposed to silver-NPs consistently over-express isoforms of metallothionein (MT1A, MT1F, MT1G, MT1X, and MT2A) [25]. AshaRani et al. reported that the MT-1 F and HO-1 were upregulated in IMR-90 cells following silver-NP treatment [22]. Kawata et al. also reported that three metallothionein genes $(\mathrm{MT} 1 \mathrm{H}, \mathrm{MT} 1 \mathrm{X}$, MT2A) were significantly upregulated in HepG2 cells exposed to silver-NPs [21]. These studies suggested that the cells protect themselves against silver NP-mediated toxicity through up-regulating metallothionein genes and oxidative stress induced genes.

On the other hand, the genes which are related to the DNA damage and apoptosis, such as DNA-damageinducible transcript 3 (DDIT3), caspase 1, and apoptosisrelated cysteine peptidase (CASP1) were up-regulated by silver NPs. Changes in chromosome related genes (24 genes up-regulated and 26 genes down-regulated) (Additional file 3 and Additional file 4) found in this study might damage the chromosomes. Apoptosis inhibitors, such as BCL2 interacting protein (HRK), BIK (BCL2-interacting killer, apoptosis-inducing), Fas apoptotic inhibitory, molecule 3 (FAIM3), apoptosis inhibitor (FKSG2), suppression of tumorigenicity 13 (ST13), growth arrest and DNA-damageinducible, alpha (GADD45A) were also significantly upregulated. This suggested that silver nanoparticles induced apoptosis via a mitochondrial pathway. Apoptosis and chromosome damage could be subsequently involved in cytotoxicity and genotoxicity.

In addition, analysis of the activating signal pathways in this study also suggested that cell cycles and the mitosis signal pathway were significantly down-regulated, which was uniquely represented at the silver-NP-hydrogel $48 \mathrm{~h}$ exposure. These pathways are considered to be closely involved in cell proliferation, apoptosis and tumorigenesis progression. There were 62 genes related to cell cycle signal pathways. Among them, 27 genes were related to mitosis pathway (Additional file 15). In these genes, cell division cycle 14 homolog A (CDC14A) showed a 13 -fold $\left(\log _{2}=-3.71\right)$ down-regulation. CDC14A is a member of the dual specificity protein tyrosine phosphatase family. It is highly similar to saccharomyces cerevisiae Cdc14, a protein tyrosine phosphatase involved in the exit of cell mitosis and initiation of DNA replication, playing a role in cell cycle control. CDC14A protein has been shown to interact with and dephosphorylate the tumor suppressor protein $\mathrm{p} 53$, and is thought to regulate the function of p53 [44]. Human CDC14A shares sequence similarity with the recently identified tumor suppressor, MMAC1/PTEN/TEP1. $\mathrm{CDC14} \mathrm{A}$ is located at chromosome band $1 \mathrm{p} 21$, a region that has been shown to exhibit loss of heterozygosity in highly differentiated breast carcinoma and malignant mesothelioma. Thus, CDC14A has been thought to be a tumor suppressor gene [44]. The down-regulation of CDC14A in this study suggested that it might play a role in the potential genotoxicity induced by silver-NP-hydrogel.

As summarized in Figure 4, the balance between anti-ROS-toxicity and DNA damage, apoptosis, mitosis inhibition of the cells could be the main events which decide the future of the cells.

\section{JAK-STAT signal transduction pathway}

The JAK-STAT (Janus kinase/signal transducers and activators of transcription) cascade is an important signal pathway which affects basic cell functions such as cell growth, differentiation and apoptosis [45]. STAT is a signal transducer and activator of transcription. It conveys or transduces the signal from the receptor-JAK (Janus Kinase) complex to the DNA in the cell nucleus [45]. In mammals, the JAK-STAT signal pathway is the principal signaling mechanism for a wide array of cytokines and growth factors $[45,46]$. Defects in JAK-STAT proteins can result in immune deficiency disease and cancer [45]. JAKs, which have tyrosine kinase activity, bind to some cell surface cytokine receptors. So, the cytokines, as ligands, through binding to the receptor would trigger activation of JAKs [46-50]. In this

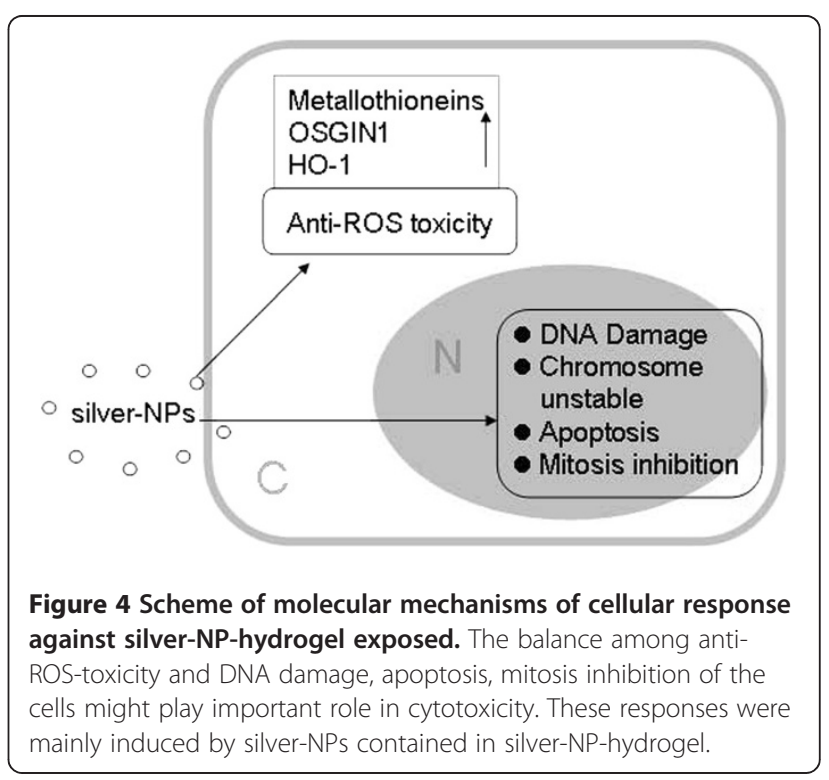


study, it was found that silver-NP-hydrogel exposure induced JAK-STAT cascade-related gene up-regulation, not only at $24 \mathrm{~h}$ exposure but also for $48 \mathrm{~h}$ exposure [Additional file 5 and Additional file 6], and implied that the silver-NPhydrogel might play a role in JAK-STAT pathway.

It was found by further analysis that many interferoninduced proteins (IFI), interferon-induced protein in the tetratricopeptide (IFIT) family, and interleukin (IL) family were up-regulated (Additional file 5 and Additional file 6). These inflammatory factors acting as ligands while they participate in immune response pathway, may also trigger the activation of JAK-STAT signal pathway through binding to the JAK receptor.

\section{Conclusions}

In summary, the silver-NP-hydrogel induced micronuleus formation in HeLa cells. The toxic effects caused by silverNP-hydrogel arrived mainly from silver-NPs. Based on DNA microarray and GO pathway analysis, the molecular response and mechanisms of toxicity induced by silver-NPhydrogel might relate to some up-regulated genes involved in fourteen theoretical activating signaling pathways and to some down-regulated genes involved in three signal pathways at $48 \mathrm{~h}$ of silver-NP-hydrogel exposure in HeLa cells. These signal pathways play important roles in metabolisms, cell communication, signal transduction, cellular defense response, transport, cell cycles and mitosis. The down-regulation of $\mathrm{CDC14A}$ via mitosis pathway suggested that it may play a role in the potential genotoxicity induced by silver-NP. The balances between anti-ROS response and DNA damage, chromosome instability and mitosis inhibition might play important roles in silver-NP induced toxicity. It was also demonstrated that activations of both JAK-STAT signal transduction pathway and immune response pathway could be involved in the mechanisms of toxicity caused by silver-NP-hydrogel.

\section{Materials and methods}

\section{Test materials and chemicals}

Silver-NP-based hydrogel (silver-NP-hydrogel) used in this study was a clinical available product, and has been used in clinic for treating cervicitis and cervical erosion of women. The product provided by Egeta Co. (Shenzhen, China, Batch Number 090701) was manufactured by simply mixing aqueous silver-NP solution (concentration of 2,000 ppm, purchased from Nanux, Korea, Cat. No. SL1105001) and hydrogel components to achieve a concentration of $0.38 \mu \mathrm{g} / \mathrm{mg}$ (silver- NP-hydrogel). The silver NPs were not coated by any compounds such as PVP, citrate or BSA. To determine the NP size distribution, silverNP-hydrogel was dissolved in water. Then, the silver particles were collected by centrifuging and placed on a cuppernet for evaluation of size distribution by TEM (Additional file 16: Figure S1). As determined through TEM, the size distribution of the nanoparticles was as follows: $3-5 \mathrm{~nm}$, 47.9\%; 5-10 nm, 50.8\%; 10-30 nm, 1.3\%. The hydrogel was composed of sterile water, glycerine, carbomer and triethanolamine (TEA). The hydrogel component alone (without silver-NP) was used as the compared control.

Cytochalasin B (Cyt-B), Mitomycin C (MMC) and Dimethyl sulfoxide (DMSO) were purchased from SigmaAldrich (USA). The Cyt-B was dissolved in DMSO (2.0 mg/ $\mathrm{ml})$, and the $\mathrm{MMC}$ was dissolved in $\mathrm{NaCl}$ solution $(10 \mu \mathrm{g} /$ $\mathrm{ml}$ ) for use as a stock solution. All solutions were sterilized by using $0.2 \mu \mathrm{m}$-pore film and stored at $-20^{\circ} \mathrm{C}$.

\section{Cell culture and treatment}

Silver-NP-hydrogel is currently a clinical product on the markets and is commonly used for treating cervicitis and cervical erosion of women. Therefore, the HeLa cell line was chosen as a cell model in this study. HeLa cells were originally purchased from RIKEN (Wako, Japan) with a RIKEN Cell line number. RCB0007. The cells were cultured in DMEM (GIBCO, USA), with 10\% FBS (GIBCO, USA) and $100 \mathrm{U} / \mathrm{ml}$ penicillin $/ 100 \mu \mathrm{g} / \mathrm{ml}$ streptomycin (GIBCO, USA), in a humidified $5 \% \mathrm{CO}_{2}$ atmosphere at $37^{\circ} \mathrm{C}$.

To determine a suitable concentration of silver-NPhydrogel for the study, a preliminary experiment was performed by adding silver-NP-hydrogel to culture medium at concentrations of 2.5, 5, 10, 20, 40, and $60 \mathrm{mg} / \mathrm{ml}$. After ultrasonic treatment (300 W, $42 \mathrm{kHz}$,) for $10 \mathrm{~min}$, the media with various concentrations of silver-NP-hydrogel was applied to cells which had been pre-cultured for $24 \mathrm{~h}$ (70-80\% confluence), and the cells were then cultured for another $24 \mathrm{~h}$. Cell viability was determined using a methyl tetrazolium (MTT) assay by measuring the optical density of the formazan product. Briefly, after the exposure to silver-NP-hydrogel solution, the cells were washed. A mixture of $20 \mu \mathrm{l}$ of MTT $(5 \mathrm{mg} / \mathrm{ml})$ and $100 \mu \mathrm{l}$ of non-phenol-red medium were added to the cells, and incubated for $4 \mathrm{~h}$. After through washes and DMSO treatment, $100 \mu \mathrm{l}$ of the supernatant of each sample was transferred for optical density (OD) detection. The assay was performed using a plate reader at a wavelength $570 \mathrm{~nm}$, with $630 \mathrm{~nm}$ as the reference wavelength. The results represented a percentage of the relative viability of cells against to the untreated control. Based on this preliminary experiment, a middle-level viability inhibition of the cells, compared to that in the non-treatment control cells, was found at a concentration (IC50) about $40 \mathrm{mg} / \mathrm{ml}$ of silver-NP-hydrogel (in culture media) which containing $15.2 \mu \mathrm{g} / \mathrm{ml}$ of silverNPs. This concentration was determined according to the concentration-relative cell viability (\%) curve equation, and the non-treatment control cell viability (OD level) was served as 100\%. An EC50 NP concentration was selected also because the EC50 or IC50 is a conventional coefficient in ISO and OECD standards for toxicity 
assessments. To minimize a possible detection of RNA species degraded from dying cells at this toxicity level, the culture dishes were thoroughly washed three times by PBS before harvesting to remove the dead cells and degraded molecules. For the gene expression microarray experiment, $40 \mathrm{mg} / \mathrm{ml}$ of silver-NP-hydrogel was used. The cells were seeded at a concentration of $5 \times 10^{5}$ cells $/ 35-\mathrm{cm}$ cell culture dish for CBMN assay, MTT assay and DNA microarray experiment. The cells were exposed to the silver-NPhydrogel for 24 and $48 \mathrm{~h}$, respectively.

\section{CBMN assay}

The CBMN assay was carried out using the protocol described as below. Briefly, the HeLa cells were seeded and maintained to $70-80 \%$ confluence at $24 \mathrm{~h}$. Silver-NPhydrogel was added to culture media at concentrations of 20,40 and $60 \mathrm{mg} / \mathrm{ml}$ respectively, and after ultrasonic treatment (300 W, $42 \mathrm{kHz}$ for $10 \mathrm{~min}$ ) the media with silverNP-hydrogel was applied to the cells. MMC $(0.1 \mu \mathrm{g} / \mathrm{ml})$ was used as a positive control, and $\mathrm{NaCl}(50 \mu \mathrm{l} / \mathrm{ml})$ was used as a negative control. The cells were then further cultured for $24 \mathrm{~h}$. After washing thoroughly with three times of PBS, Cytochalasin-B (final conc., $3 \mu \mathrm{g} / \mathrm{ml}$ ) was added to the cells, and the cells were cultured for another $18 \mathrm{~h}$. The cells were subsequently collected. After a hypotonic treatment in $2 \mathrm{ml}$ of $0.075 \mathrm{M} \mathrm{KCl}$ at room temperature for $5 \mathrm{~min}$, the cells were fixed using methyl alcohol:acetic acid (3:1). The cells were then placed onto a slide, dried at room temperature, and stained using 4\% Giemsa solution ( $\mathrm{pH}$ 6.8) for $30 \mathrm{~min}$.

The slides were scored at $400 \times$ magnification blindly by two investigators separately. The micronucleation frequency (MNF, \%) was determined for 1000 binucleated cells (BNCs).

\section{Total RNA isolation and DNA microarray}

The cells reached 70-85\% confluence at both $24 \mathrm{~h}$ and $48 \mathrm{~h}$ cultures with the treatment of silver-NP-hydrogel at a concentration of $40 \mathrm{mg} / \mathrm{ml}$, and almost a full conference in the control cultures with non-treatment (Figure 2). The total RNA from each sample was extracted from the HeLa cells using ISOGEN RNA isolation reagent (Nippon gene, Japan) according to the instructions provided by the manufacturer. After decontamination treatment of genomic DNA using DNase I digestion, the quality and integrity of the RNA samples were determined by appearance of the distinct $28 \mathrm{~S}$ and $18 \mathrm{~S}$ bands of ribosomal RNA on agarose gel electrophoresis. Total RNA purity was measured spectrophotometrically by the absorbance ratio $260 / 280 \mathrm{~nm}$. Results ranged between 1.7-2.1.

A gene expression study was conducted using "Two-color microarray-based gene expression analysis" (Agilent technologies, USA, Whole Human Genome Microarray 4x44K, G4110F containing 41000 of DNA oligomer unique probes). Briefly, $1 \mu \mathrm{g}$ of each sample of RNA was amplified using an
Amino Allyl MessageAmp II aRNA Amplification Kit (Ambion, USA). Amplified RNA (aRNA) was labeled using Cy5 and $\mathrm{Cy} 3$ according to the instructions provided by the manufacturer. The silver-NP-hydrogel or hydrogel-alone exposure samples were labeled with $\mathrm{Cy} 5$, and untreated cells were labeled with Cy3 which was used as control against the treated Cy5-labeled sample. After hybridizing the samples for $16 \mathrm{~h}$ at $65^{\circ} \mathrm{C}$, the gene chips were washed. The hybridized chips were fluorescently scanned with a microarray scanner (GenePix 4000B, USA) to collect the images. The ratios of intensity $\left(\log _{2} \mathrm{Cy} 5 / \mathrm{Cy} 3\right)$ were calculated and normalized with GenePixPro 6.1 software. Filtering of the results was done as follows: genes were considered as up-regulated when the $\log _{2} \mathrm{Cy} 5 / \mathrm{Cy} 3$ ratio was higher than 1 (Cy5/Cy3 was higher than 2) and as downregulated when the $\log _{2} \mathrm{Cy} 5 / \mathrm{Cy} 3$ ratio was lower than -1 (Cy5/Cy3 was lower than -2). Genes were considered as unregulated when the $\log _{2} \mathrm{Cy} 5 / \mathrm{Cy} 3$ ratio was between 1 and -1 . The GO pathway data was further classified into functional categories. The genes, which were consistently up-regulated and down-regulated at $48 \mathrm{~h}$ of silver-NPhydrogel exposure, were tabled for further analysis.

\section{Gene ontology analysis of gene expression}

To determine biological relevant gene ontology terms (GO, provided by NCBI) of differentially expressed genes in HeLa cells, the software "PANTHER", was used. It provides gene expression data analysis/Comparison of gene lists (http://www.pantherdb.org/tools/genexAnalysis. jsp). The analysis was performed using Unigene ID as the identifier for biological process categories.

\section{Real-time PCR}

The reliability of the gene expression profile was validated by real-time PCR (SYBR Green method) for five selected genes, viz., interleukin 1, alpha (IL1A); heme oxygenase (decycling) 1(HMOX1); DNA-damage-inducible transcript 3 (DDIT3); metallothionein 1 F (MT1F) and plateletderived growth factor receptor, beta polypeptide (PDGFRB)

\begin{tabular}{lll}
\multicolumn{2}{l}{ Table $\mathbf{5}$ Primers used in real-time PCR } \\
\hline Gene & GeneBank & Primer Sequence $\mathbf{5}^{\prime} \rightarrow \mathbf{3}^{\prime}$ \\
\hline Actin & NM 001101 & $\begin{array}{l}\text { Forward Primer: CATGTACGTTGCTATCCAGGC } \\
\text { Reverse Primer: CTCCTTAATGTCACGCACGAT }\end{array}$ \\
\hline MT1F & NM 005949 & $\begin{array}{l}\text { Forward Primer: CCCACTGCTTCTTCGCTTCT } \\
\text { Reverse Primer: GAGAAAGGTTGCCTGGCATC }\end{array}$ \\
\hline IL1A & NM 000575 & $\begin{array}{l}\text { Forward Primer: AATGACGCCCTCAATCAAAGTA } \\
\text { Reverse Primer: CTCCTTCAGCAGCACTGGTTG }\end{array}$ \\
\hline HMOX 1 & NM002133 & $\begin{array}{l}\text { Forward Primer: AAGAGGCCAAGACTGCGTTC } \\
\text { Reverse Primer: GAGTGTAAGGACCCATCGGAGA }\end{array}$ \\
\hline DDIT 3 & NM 004083 & $\begin{array}{l}\text { Forward Primer: GTCCTGTCTTGATGAAAATGG } \\
\text { Reverse Primer: GTGCTTGTACCTCTGCTGG }\end{array}$ \\
\hline PDGFRB & NM 002609 & $\begin{array}{l}\text { Forward Primer: GAGACTGTTGGGCGAGGTTA } \\
\text { Reverse Primer: GAGATGGTTGAGGGGTTGAC }\end{array}$ \\
\hline
\end{tabular}


at $48 \mathrm{~h}$ exposure of silver-NP-hydrogel. Real-time PCR was performed using the ABI 7900 HT Fast RealTime PCR system (Applied Biosystem, USA). Briefly, total RNA $(25 \mu \mathrm{g})$ from each sample was DNase I digested by the following reactions: RQ1 RNase-Free DNase 10× Reaction Buffer (5 $\mu \mathrm{l})$, RQ1 RNase-Free DNase I (2 $\mu$ l,Promega, USA), Recombinant RNasin RNase Inhibitor (1 $\mu \mathrm{l}$, Promega, USA), Nuclease-Free Water to total volume $50 \mu$, with incubation for $30 \mathrm{~min}$ at $37^{\circ} \mathrm{C}$. Following purification of DNase I digested RNA, $2 \mu \mathrm{g}$ of RNA was reversetranscribed into cDNA by using M-MLV reverse transcriptase (Invitrogen, USA). One $\mu$ l of the cDNA sample was added to the PCR mixture which was composed of $10 \mu \mathrm{l}$ of Power SYBR Green PCR Master Mix (Applied Biosystem, USA), $0.5 \mu \mathrm{l}$ of forward primer $(10 \mu \mathrm{M})$ and $0.5 \mu \mathrm{l}$ of reverse primer $(10 \mu \mathrm{M})$. Nuclease-free water was added to bring the volume up to $20 \mu \mathrm{l}$, and the mixture was subjected to PCR amplification. The primers used in this study are listed in Table 5. The threshold cycles $(\mathrm{Ct})$ in each sample were measured by comparing their amplification with that of standard samples and was normalized to that of the housekeeping gene actin. An average $\mathrm{Ct}$ of triplicate detection for each gene, $\Delta \mathrm{Ct}$ (Detecting gene House keeping gene); and $\Delta \Delta \mathrm{Ct}$ (Test sample-Control sample) was obtained; finally calculated $2^{-\Delta \Delta \mathrm{Ct}}$ and represented as the differential expression of test genes.

\section{Statistical analysis}

The data were represented as the mean \pm SD. The CBMN assay was repeated three independent times. The data was statistically analyzed using the SPSS, version 12.0.1), the $t$-test, ANOVA and Dunnett test (2-sided). Differences were considered significant if the $P$-value was less than 0.05 .

\section{Additional files}

Additional file 1: Up-regulated genes in cells exposed to silver-NPhydrogel for $24 \mathrm{~h}$. Fold-change is logarithmic ratio (log2 ratio) to expression level in control.

Additional file 2: Down-regulated genes in cells exposed to silver-NPhydrogel for $24 \mathrm{~h}$. Fold-change is logarithmic ratio (log2 ratio) to expression level in control.

Additional file 3: Up-regulated genes in cells exposed to silver-NPshydrogel for $48 \mathrm{~h}$. Fold-change is logarithmic ratio (log2 ratio) to expression level in control.

Additional file 4: Down-regulated genes in cells exposed to silver-NPshydrogel for $48 \mathrm{~h}$. Fold-change is logarithmic ratio (log2 ratio) to expression level in control.

Additional file 5: Up-regulated genes in cells exposed to Hydrogel for $24 \mathrm{~h}$. Fold-change is logarithmic ratio (log2 ratio) to expression level in control.

Additional file 6: Down-regulated genes in cells exposed to Hydrogel for $24 \mathrm{~h}$. Fold-change is logarithmic ratio (log2 ratio) to expression level in control.

Additional file 7: Up-regulated genes in cells exposed to Hydrogel for 48h. Fold-change is logarithmic ratio (log2 ratio) to expression level in control.

Additional file 8: Down-regulated genes in cells exposed to Hydrogel for $48 \mathrm{~h}$. Fold-change is logarithmic ratio (log2 ratio) to expression level in control.

Additional file 9: Common up-regulated genes in cells exposed to silver-NP-hydrogel for $24 \mathrm{~h}$ and $48 \mathrm{~h}$. Fold-change is logarithmic ratio (log2 ratio) to expression level in control.

Additional file 10: Common down-regulated genes in cells exposed to silver-NP-hydrogel for $24 \mathrm{~h}$ and $48 \mathrm{~h}$. Fold-change is logarithmic ratio (log2 ratio) to expression level in control.

Additional file 11: Common up-regulated genes in cells exposed to hydrogel for $24 \mathrm{~h}$ and $48 \mathrm{~h}$. Fold-change is logarithmic ratio (log2 ratio) to expression level in control.

Additional file 12: Common down-regulated genes in cells exposed to hydrogel for $24 \mathrm{~h}$ and $48 \mathrm{~h}$. Fold-change is logarithmic ratio (log2 ratio) to expression level in control.

Additional file 13: Common up-regulated genes in cells exposed to hydrogel and silver-NP-hydrogel for 48h. Fold-change is logarithmic ratio (log2 ratio) to expression level in control.

Additional file 14: Common down-regulated genes in cells exposed to hydrogel and silver-NP-hydrogel for 48h. Fold-change is logarithmic ratio (log2 ratio) to expression level in control.

Additional file 15: Down-regulated genes related to mitosis pathway at silver-NP-hydrogel treatment for $48 \mathrm{~h}$.

Additional file 16: Figure $\mathbf{S 1}$. The size and size distribution of the silver nanoparticles determined by transmission electron microscopy (TEM). A: $X$ 10000, bar $=200 \mathrm{~nm} ; \mathrm{B}: \times 20000, \mathrm{bar}=100 \mathrm{~nm}$.

\section{Abbreviations}

silver-NP: Silver nanoparticle; silver-NP-hydrogel: Silver nanoparticle based hydrogel; CBMN: Cytokinesis-block micronucleus; ROS: Reactive oxygen species; Cyto-B: Cytochalasin B; DMSO: Dimethyl sulfoxide; MMC: Mitomycin C; MTT: Methyl tetrazolium; GO: Gene ontology; MNF: Micronucleation frequency; BNCs: Binucleated cells; TEA: Triethanolamine; CDC14A: Cell division cycle 14 homolog A; JAK-STAT: Janus kinase/signal transducers and activators of transcription; IFI: Interferon-induced proteins; IFIT: Interferoninduced protein in the tetratricopeptide; IL: Interleukin; IL1A: Interleukin 1 alpha; HMOX1: Heme oxygenase (decycling); DDIT3: DNA-damage-inducible transcript 3; MT1F: Metallothionein 1 F; PDGFRB: Platelet-derived growth factor receptor beta polypeptide.

\section{Competing interests}

The authors declare that they have no competing interests.

\section{Acknowledgements}

This study was financially supported by the Human Resources and Social Security Office of China (HRSSO Letter [2009], No. 416), the Beijing Natural Science Foundation of China (No. 3112024) and the Open Research Fund of State Key Laboratory of Bioelectronics, Southeast University, China; National Key Technology Research and Development Program of the Ministry of Science and Technology of China (2012BAI22B01, 2012BAK26B00).

\section{Author details}

${ }^{1}$ Institute for Medical Devices Control, National Institutes for Food and Drug Control (NIFDC), No. 2 Temple of Heaven, Beijing 100050, China. ${ }^{2}$ Baotou Medical College, Inner Mongolia University of Science \& Technology, Baotou 014010, China. Interdisciplinary Laboratory for Nanoscale Science and Technology, National Institute for Materials Science, 1-2-1 Sengen, Tsukuba, Ibaraki 305-0047, Japan. ${ }^{4}$ Goldman School of Dental Medicine, Boston University, 801 Albany Street, Suite 200, Boston, MA 02118-2392, USA.

\section{Authors' contributions}

Liming Xu participated in the design of study, sequence alignment, performed the statistical analysis and drafted the manuscript. Xuefei Li carried out the genotoxic assay, participated in the sequence alignment and drafted the manuscript. Taro Takemura and Nobutaka Hanagata carried out 
the DNA microarray experiment and data analysis. Gang Wu and Laisheng Lee Chou participated in the design of study, data analysis and coordination, and drafting manuscript. All authors read and approved the final manuscript.

Received: 7 December 2011 Accepted: 1 May 2012

Published: 1 May 2012

\section{References}

1. Lee JH, Chae JD, Kim DG, Hong SH, Lee WM, Ki M: Comparison of the efficacies of silver-containing dressing materials for treating a full-thickness rodent wound infected by methicillin-resistant Staphylococcus aureus. Korean J Lab Med 2010, 30:20-27.

2. Elliott $C$ : The effects of silver dressings on chronic and burns wound healing. Br J Nurs 2010, 19:S32-S36.

3. Gabriel MM, Mayo MS, May LL, Simmons RB, Ahearn DG: In vitro evaluation of the efficacy of a silver-coated catheter. Curr Microbiol 1996, 33:1-5.

4. Ahearn DG, Grace DT, Jennings MJ, Borazjani RN, Boles KJ, Rose LJ, Simmons $\mathrm{RB}$, Ahanotu EN: Effects of hydrogel/silver coatings on in vitro adhesion to catheters of bacteria associated with urinary tract infections. Curr Microbiol 2000, 41:120-125.

5. Wu J, Hou S, Ren D, Mather PT: Antimicrobial properties of nanostructured hydrogel webs containing silver. Biomacromolecules 2009, 10:2686-2693.

6. Gils PS, Ray D, Sahoo PK: Designing of silver nanoparticles in gum arabic based semi-IPN hydrogel. Int J Biol Macromol 2010, 46:237-244.

7. Thomas V, Yallapu MM, Sreedhar B, Bajpai SK: A versatile strategy to fabricate hydrogel-silver nanocomposites and investigation of their antimicrobial activity. J Colloid Interface Sci 2007, 315:389-395.

8. Ji JU, Jung JH, Kim SS, Yoon JU, Park JD, Choi BS, Chung YH, Kwon IU, Jeong J, Han BS, Shin JH, Sung JH, Song KS, Yu IJ: Twenty-eight-day inhalation toxicity study of silver nanoparticles in Sprague-Dawley rats. Inhal Toxicol 2007, 19:857-871.

9. Sung JH, Ji JH, Yoon JU, Kim DS, Kim DS, Song MY, Jeong J, Han BS, Han JH, Chung YH, Kim J, Kim TS, Chang HK, Lee EJ, Lee JH, Yu IJ: Lung function changes in Sprague-Dawley rats after prolonged inhalation exposure to silver nanoparticles. Inhal Toxicol 2008, 20:567-574.

10. Sung JH, Ji JH, Park JD, Yoon JU, Kim DS, Jeon KS, Song MY, Jeong J, Han BS, Han JH, Chung YH, Chang HK, Lee JH, Cho MH, Kelman BJ, Yu IJ: Subchronic inhalation toxicity of silver nanoparticles. Toxicol Sci 2009, 108:452-461.

11. Kim YS, Kim JS, Cho HS, Rha DS, Kim JM, Park JD, Choi BS, Lim R, Chang HK,

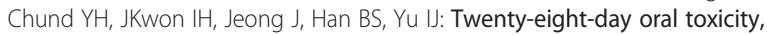
genotoxicity, and gender-related tissue distribution of silver nanoparticles in Sprague-Dawley rats. Inhal Toxicol 2008, 20:575-583.

12. Kim YS, Song MY, Park JD, Song KS, Ryu HR, Chung YH, Chang HK, Lee JH, Oh KH, Kelman BJ, Hwang IK, Yu IJ: Subchronic Oral toxicity of silver nanoparticles. Part Fibre Toxicol 2010, 7:20.

13. Tang J, Xiong L, Wang S, Wang J, Liu L, Li J, Yuan F, Xi T: Distribution, translocation and accumulation of silver nanoparticles in rats. J Nanosci Nanotechnol 2009, 9:4924-4932.

14. Tang J, Xiong L, Zhou G, Wang S, Wang J, Liu L, Jiage Li, Yuan F, Lu S, Wan $Z$, Chou $L, X i T$ : Silver nanoparticles crossing through and distribution in the blood-brain barrier in vitro. J Nanosci Nanotechnol 2010, 10: 6313-6317.

15. Braydich-Stolle L, Hussain S, Schlager JJ, Hofmann MC: In vitro cytotoxicity of nanoparticles in mammalian germline stem cells. Toxicol Sci 2005 , 88:412-419.

16. Crewlich C, Kittler S, Epple M, Muhr G, Koller M: Studies on the biocompatibility and the interaction of silver nanoparticles with human mesenchymal stem cells (hMSCs). Langenbecks Arch Surg 2009, 394 495-502.

17. Hackenberg S, Scherzed A, Kessler M, Hummel S, Technau A, Froelich K, Ginzkey C, Koehler C, Hagen R, Kleinsasser N: Silver nanoparticles: evaluation of DNA damage, toxicity and functional impairment in human mesenchymal stem cells. Toxicol Lett 2010, 201:27-33.

18. Greulich C, Diendorf J, Simon T, Eggeler G, Epple M, Köller M: Uptake and intracellular distribution of silver nanoparticles in human mesenchymal stem cells. Acta Biomater 2011, 7:347-354.

19. Hussain SM, Hess KL, Gearhart JM, Geiss KT, Schlager JJ: In vitro toxicity of nanoparticles in BRL 3A rat liver cells. Toxicol In Vitro 2005, 19:975-983.

20. Hsin YH, Chen CF, Huang S, Shih TS, Lai PS, Chueh PJ: The apoptotic effect of nanosilver is mediated by a ROS- and JNK-dependent mechanism involving the mitochondrial pathway in NIH3T3 cells. Toxicol Lett 2008, 179:130-139.

21. Kawata K, Osawa M, Okabe S: In vitro Toxicity of silver nanoparticles at nanocytotoxic doses to HepG2 human hepatoma cells. Environ Sci Technol 2009, 43:6046-6051.

22. AshaRani PV, Hande PM, Valiyaveettil S: Anti-proliferative activity of silver nanoparticles. BMC Cell Biology 2009, 10:65-79.

23. AshaRani PV, Low Kah MG, Hande MP, Valiyaveettil S: Cytotoxicity and genotoxicity of silver nanoparticles in human cells. ACS nano 2009, 3: 279-290.

24. Kim HR, Kim MJ, Lee SY, Oh SM, Chung KH: Genotoxic effects of silver nanoparticles stimulated by oxidative stress in human normal bronchial epithelial (BEAS-2B) cells. Mutat Res 2011, 726:129-135.

25. Xu L, Takemura T, Xu M, Hanagata N: Toxicity of silver nanoparticles as assessed by global gene expression analysis. Materials Express 2011, 1: 74-79.

26. Kumari M, Mukherjee A, Chandrasekaran N: Genotoxicity of silver nanoparticles in Allium cepa. Sci Total Environ 2009, 407:5243-5246.

27. Boonstra J, Post JA: Molecular events associated with reactive oxygen species and cell cycle progression in mammalian cells. Gene 2004, 337: $1-13$.

28. Xia T, Kovochich M, Brant J, Hotze M, Sempf J, Oberley T, Sioutas C, Yeh Jl, Wiesner MR, Nel AE: Comparison of the abilities of ambient and manufactured nanoparticles to induce cellular toxicity according to an oxidative stress paradigm. Nano Lett 2006, 6:1794-1807.

29. Carlson C, Hussain SM, Schrand AM, Braydich-Stolle LK, Hess KL, Jones RL, Schlager JJ: Unique cellular interaction of silver nanoparticles: size-dependent generation of reactive oxygen species. J Phys Chem 2008, 112:13608-13619.

30. Fenech M: The advantages and disadvantages of the cytokinesis-block micronucleus method. Mutat Res 1997, 392:11-18.

31. Chou L: Molecular biocompatibility. J Dent Res 1995, 74:190-193.

32. Lu X, Bao X, Huang Y, Qu Y, Lu H, Lu Z: Mechanisms of cytotoxicity of nickel ions based on gene expression profiles. Biomaterials 2009, 30: $141-148$.

33. Lu X, Lu H, Zhao L, Yang Y, Lu Z: Genome-wide pathways analysis of nickel ion-induced differential genes expression in fibroblasts. Biomaterials 2010, 31:1965-1973.

34. Kim JS, Sung JH, Ji JH, Song KS, Lee JH, Kang CS, Yu IJ: In vivo genotoxicity of silver nanoparticles after 90-day silver nanoparticle inhalation exposure. Saf Health Work 2011, 2:34-38.

35. Xu L, Chen L, Dong Z, Wang J, Wang Z, Shao A: In vivo toxicity in reproductive organs of rabbit and in vitro cytotoxicity of silver nanoparticle based-hydrogel. Chi J Pharm Anal 2012, 2:194-201.

36. Becker H, Herzberg F, Schulte A, Kolossa-Gehring M: The carcinogenic potential of nanomaterials, their release from products and options for regulating them. Int J Hyg Environ Health 2011, 214:231-238.

37. Sanchez VC, Pietruska JR, Miselis NR, Hurt RH, Kane AB: Biopersistence and potential adverse health impacts of fibrous nanomaterials: what have we learned from asbestos? Wiley Interdiscip Rev Nanomed Nanobiotechnol 2009, 1:511-529.

38. Tsui MT, Wang WX: Biokinetics and tolerance development of toxic metals in Daphnia magna. Environ Txicol Chem 2007, 26:1023-1032.

39. Min KS: Physiological significance of metallothionein in oxidative stress. Yakugaku Zasshi 2007, 127:695-702.

40. Woo S, Yum S, Jung JH, Shim WJ, Lee CH, Lee TK: Heavy metal-induced differential gene expression of metallothionein in Javanese medaka, Oryzial javanicus. Mar Biotechnol (NY) 2006, 8:654-662.

41. Clark JE, Foresti R, Green CJ, Motterlini R: Dynamics of haem oxygenase-1 expression and bilirubin production in cellular protection against oxidative stress. Biochem J 2000, 384:615-619.

42. Elbirt KK, Bonkovsky HL: Heme oxygenase: recent advances in understanding its regulation and role. Proc Assoc Am Physicians 1999, 111:438-447.

43. Rahman MF, Wang J, Patterson TA, Saini UT, Robinson BL, Newport GD Murdock RC, Schlager JJ, Hussain SM, Ali SF: Expression of genes related to oxidative stress in the mouse brain after exposure to silver-25 nanoparticles. Toxicol Lett 2009, 187:15-21.

44. Wong AK, Chen Y, Lian L, Ha PC, Petersen K, Laity K, Carillo A, Emerson M, Heichman K, Gupte J, Tavtigian SV, Teng DH: Genomic structure, chromosomal location, and mutation analysis of the human CDC14A gene. Genomics 1999, 59:248-251. 
45. Aaronson DS, Horvath CM: Road Map for Those Who Don't Know JAK-STAT. Science 2002, 296:1653-1655.

46. O'Shea JJ, Gadina M, Schreiber RD: Cytokine Signaling: new Surprises in the Jak/Stat Pathway. Cell 2002, 109:S121-S131.

47. Imada K, Leonard WJ: The Jak-STAT pathway. Mol Immunol 2000, 37:1-11.

48. Hebenstreit D, Horejs-Hoeck J, Duschl A: JAK/STAT-dependent gene regulation by cytokines. Drug News Perspect 2005, 18:243-249.

49. Espert L, Dusanter-Fourt I, Chelbi-Alix MK: Negative regulation of the JAK/ STAT: pathway implication in tumorigenesis. Bull Cancer 2005, 92:845-857.

50. Rakesh K, Agrawal DK: Controlling cytokine signaling by constitutive inhibitors. Biochem Pharmacol 2005, 70:649-657.

doi:10.1186/1477-3155-10-16

Cite this article as: Xu et al:: Genotoxicity and molecular response of silver nanoparticle (NP)-based hydrogel. Journal of Nanobiotechnology 2012 10:16

\section{Submit your next manuscript to BioMed Central and take full advantage of:}

- Convenient online submission

- Thorough peer review

- No space constraints or color figure charges

- Immediate publication on acceptance

- Inclusion in PubMed, CAS, Scopus and Google Scholar

- Research which is freely available for redistribution 